\title{
Neuropeptide Induction of Cyclic GMP Increases in the Insect CNS: Resolution at the Level of Single Identifiable Neurons
}

\author{
John Ewer, ${ }^{1}$ Jan De Vente, ${ }^{2}$ and James W. Truman' \\ 'Zoology Department, University of Washington, Seattle, Washington 98195 and ${ }^{2}$ Department of Psychiatry and \\ Neuropsychology, Section of Neuropsychology, 6200 MD Maastricht, The Netherlands
}

In insects, the neuropeptide eclosion hormone (EH) acts on the CNS to evoke the stereotyped behaviors that cause ecdysis, the shedding of the cuticle at the end of each molt. Concomitantly, EH induces an increase in cyclic GMP (cGMP). Using antibodies against this second messenger, we show that this increase is confined to a network of $\mathbf{5 0}$ peptidergic neurons distributed throughout the CNS. Increases appeared $\mathbf{3 0}$ min after EH treatment, spread rapidly throughout these neurons, and were extremely long lived. We show that this response is synaptically driven, and does not involve the soluble, nitric oxide (NO)-activated, guanylate cyclase. Stereotyped variations in the duration of the cGMP response among neurons suggest a role in coordinating responses having different latencies and durations.

IKey words: eclosion hormone, cGMP, ecdysis, nitric oxide, neuropeptide, motor program, behavior]

The cyclic nucleotide cyclic $3^{\prime}, 5^{\prime}$-guanosine monophosphate (cGMP) is an important intracellular second messenger in both vertebrate and invertebrate tissues, mediating the actions of a wide variety of ligands that include transmitters, peptides, hormones, toxins and drugs. For example, in vertebrates it has been implicated as a second messenger in diverse actions such as smooth muscle relaxation, natriuresis, photoreception, olfaction, and activity-dependent depression of synaptic strength. In invertebrates CGMP has been shown to be involved in triggering stage-specific behaviors, in muscle cell death, and in regulating muscle energy metabolism (Garthwaite, 1991; Goy, 1991; Latorre et al., 1991; Schmidt et al., 1993). cGMP is generated by several distinct pathways and may act directly on effector molecules or indirectly via protein kinases and phosphodiesterases (Garthwaite, 1991; Goy, 1991; Butt et al., 1993; Schmidt et al., 1993). As a result of this complexity, the scope of cGMP-mediated phenomena has only started to be assessed.

In the moth Manduca sexta, the insect peptide eclosion hormone (EH) acts at the end of each molt to cause ecdysis, the process of shedding of the old cuticle (Truman, 1992). The peptide that is released into the blood has a variety of effects

\footnotetext{
Received Apr. 18, 1994; revised June 8, 1994; accepted June 15, 1994.

We are grateful to Dr. Heinrich Dirksen for his gift of anti-CCAP antibody. We thank Dr. Monte Westerfield for comments on the manuscript. This work was supported by a postdoctoral grant from the Muscular Dystrophy Association to J.E., and NSF Grant IBN-9219742 to J.W.T., and NIH shared instrumentation Grant S10 RR04646.

Correspondence should be addressed to John Ewer at the above address.

Copyright (c) 1994 Society for Neuroscience $0270-6474 / 94 / 147704-09 \$ 05.00 / 0$
}

on peripheral tissues including increasing cuticle extensibility, inducing secretion by dermal glands, and causing the death of specific sets of muscles. EH is also released locally within the CNS where it triggers the series of stereotyped motor programs that underlie the ecdysis behaviors. Both the central and peripheral actions of $\mathrm{EH}$ have been shown to involve increases in cGMP (Truman et al., 1979; Schwartz and Truman, 1984; Morton and Truman, 1985).

Here we report that $\mathrm{EH}$ induces, as part of its normal action, a dramatic and long-lasting increase in CGMP immunoreactivity (cGMP-IR) in identified peptidergic neurons. We show that most of this increase in CGMP is a synaptically mediated response, and is therefore not due to the direct action of $\mathrm{EH}$ on these cells. The time course of this cGMP increase differs markedly among different neurons, suggesting a mechanism whereby brief exposure to a neuropeptide can trigger long-lasting, coordinated, changes in CNS activity.

\section{Materials and Methods}

Experimental animals, injections, and surgical procedures Animals. Manduca sexta larva were raised on artificial diet under a 17 $\mathrm{L}, 7 \mathrm{D}$ photoperiod regime at $26^{\circ} \mathrm{C}$. Animals that were progressing to the molt to the fifth instar larvae were staged using external morphological markers (Copenhaver and Truman, 1982), and maintained at $27-29^{\circ} \mathrm{C}$

EH injections. Pharate fifth instar larvae were selected $2 \mathrm{hr}$ after the appearance of gas in the old head capsule, a time that is $2-3 \mathrm{hr}$ prior to normal EH release (Copenhaver and Truman, 1982), and injected with $>0.1$ units of $E H$. The eclosion hormone used in these studies was produced by a recombinant baculovirus (Eldridge et al., 1991). The peptide was diluted in saline (Ephrussi and Beadle, 1936) containing 10 $\%$ acetonitrile (Fisher), and $0.1 \mathrm{mg} / \mathrm{ml}$ bovine serum albumin (Sigma Chemical Co.).

Sodium nitroprusside injections. Pharate fifth instar larvae were selected as described above and injected with $10 \mu \mathrm{l}$ of $50 \mathrm{~mm}$ sodium nitroprusside (SNP; Sigma Chemical Co.). Based on the animal's body weight, such an injection should result in a final concentration of approximatcly $0.5 \mathrm{~mm}$ in the blood.

Nerve cord transections. Pharate fifth instar larvae were anesthetized under a stream of $\mathrm{CO}_{2}$, and submerged under cold saline (Ephrussi and Beadle, 1936). A small incision was made in the body wall and the connective between a particular pair of ganglia transected. The animal was then sutured (with 6-0 braided silk suture; Ethicon), and injected with $>0.1$ units of EH. For cuts performed after EH injection, larvae were anesthetized for $1 \mathrm{~min}$ at the designated time under $\mathrm{CO}_{2}$, submerged under cold saline, and operated as described above. The entire operation takes 3-5 min.

\section{Immunohistochemistry}

anti-cGMP. The entire CNS was dissected under cold saline and fixed overnight in $4 \%$ buffered paraformaldehyde, at room temperature. The nerve cords were then rinsed in phosphate-buffered saline (PBS), and treated in $0.5 \mathrm{mg} / \mathrm{ml}$ collagenase (type IV; Sigma Chemical Co.) in PBS 

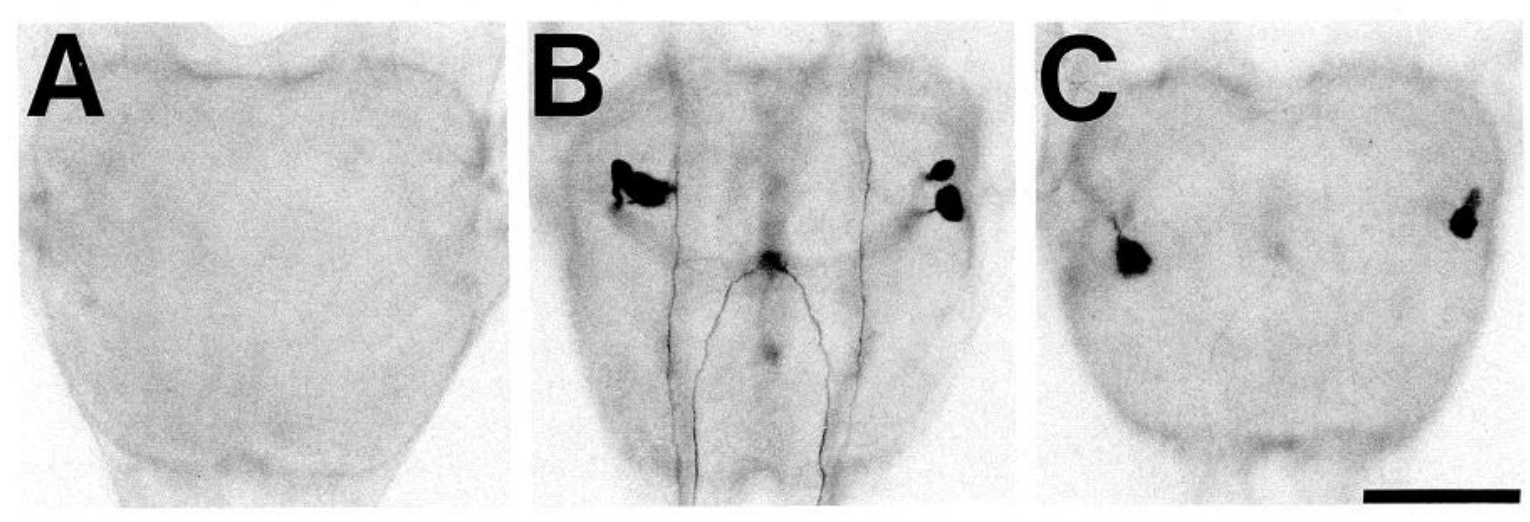

Figure 1. $A-C$, Pattern of cGMP-IR in the third thoracic ganglion of Manduca sexta larvae dissected at, in $A, 2-3 \mathrm{hr}$ prior to EH release; $B$, ecdysis; and $C, 3 \mathrm{hr}$ after ecdysis. Scale bar, $150 \mu \mathrm{m}$.

$+0.1 \%$ Triton-X (PBST) for $30 \mathrm{~min}$ at room temperature. They were then run up and down a graded methanol series, rinsed $3 \times 10$ ' in PBST, and incubated for $36 \mathrm{hr}$ in rabbit anti-cGMP antibody (1:1000; De Vente et al., 1987). The CNSs were then rinsed $4 \times 10^{\prime}$ in PBST, and incubated in biotinylated anti-rabbit antibody (1:200; Vector Laboratories) for $2 \mathrm{hr}$ at room temperature. They were then processed using the avidin-biotin-HRP system provided in an ABC kit (Vector Laboratories) using $0.5 \mathrm{mg} / \mathrm{ml}$ diaminobenzidine (DAB) $+0.003-0.01 \%$ $\mathrm{H}_{2} \mathrm{O}_{2}$ (Sigma Chemical Co.), dehydrated and mounted in DPX (Fluka).

Specificity control. In order to confirm the identity of the antigen recognized by the anti-cGMP antibody in Manduca ganglia the primary antibody was preincubated with various concentrations of cGMP, GMP, or cAMP (Sigma Chemical Co.), for $1 \mathrm{hr}$ at room temperature prior to application to the tissue.

Anti-cGMP + anti-CCAP. For these double labels the tissue was first processed for anti-cGMP or anti-CCAP (1:800, kindly provided by Dr. Heinrich Dirksen) immunoreactivity as described above, except that avidin-FITC (1:1000, Vector Laboratories) or avidin-Texas red (1:200; Vector Laboratories) was used instead of an HRP-based detection system. The tissue was then washed $4 \times 10^{\prime}$ in PBST, and processed for anti-CCAP or anti-cGMP, and detected using the appropriate avidinfluorochrome conjugate. The tissue was then mounted in $80 \%$ glycerol/ $2 \% n$-propyl-gallate (to reduce photobleaching) and viewed using confocal microscopy (Bio-Rad). Singly labeled preparations, as well as double-labeled ones in which the primaries were detected using either of the two fluorochromes were also examined, to control for cross reactivity and "bleed-through" of the FITC emissions into the Texas red channel.

Signal quantification. (1) Qualitative: cGMP-IR was quantitated subjectively using permanent, DAB-stained preparations. A score of 3 was given for intensely stained cells; a score of 2 if the staining was weaker, but both the cell body and its main arbor were visible; a score of 1 when only the cell body was visible, and 0 if cGMP-IR was not apparent. (2) Quantitative: cGMP-IR was quantitated using confocal microscopy on fluorescently labeled preparations. Tissues were prepared for cGMP immunoreactivity as described above, using the avidin-Cy5 fluorochrome (Jackson Laboratories) at a concentration 1:500. In our hands this fluorochrome gives a lower background, and produces a stronger signal that is less attenuated over the $\sim 150 \mu \mathrm{m}$ thickness of a Manduca ganglion than do Texas red-and FITC-based detection systems. Others have made similar observations (Mesce et al., 1993). CNSs to be compared were processed simultaneously, and, whenever possible, in the same vial. They were then mounted as described above, and viewed using a Bio-Rad confocal microscope. For each cell, an optical section was collected at a depth that produced the maximum average intensity over the cell body. The change in signal intensity due solely to depth was compensated for each cell by adjusting the gain to produce a background level of 6 . This corresponded to $5-6 \%$ of the maximal response, and was subtracted from the values reported in see Table 2 . Since the detection system shows some nonlinearities at high and low intensities, the values reported should be taken as being approximate.

\section{Results}

EH triggers an increase in $C G M P-I R$ in a small number of neurons in the Manduca $C N S$

Measurements of the levels of cGMP found in the extracts of Manduca nervous systems taken at various times after EH injection showed that this peptide produced a sustained increase in the levels of cGMP in the CNS (Morton and Truman, 1985). To identify the cells that are responsible for this increase in cGMP we stained the CNS of ecdysing fifth instar animals using antibodies that recognize cGMP in fixed tissue (De Vente et al., 1987). As shown in Figure 1, the thoracic (T) ganglia of such animals each had four neurons that showed strong cGMP immunoreactivity (cGMP-IR). Importantly, these cells were not
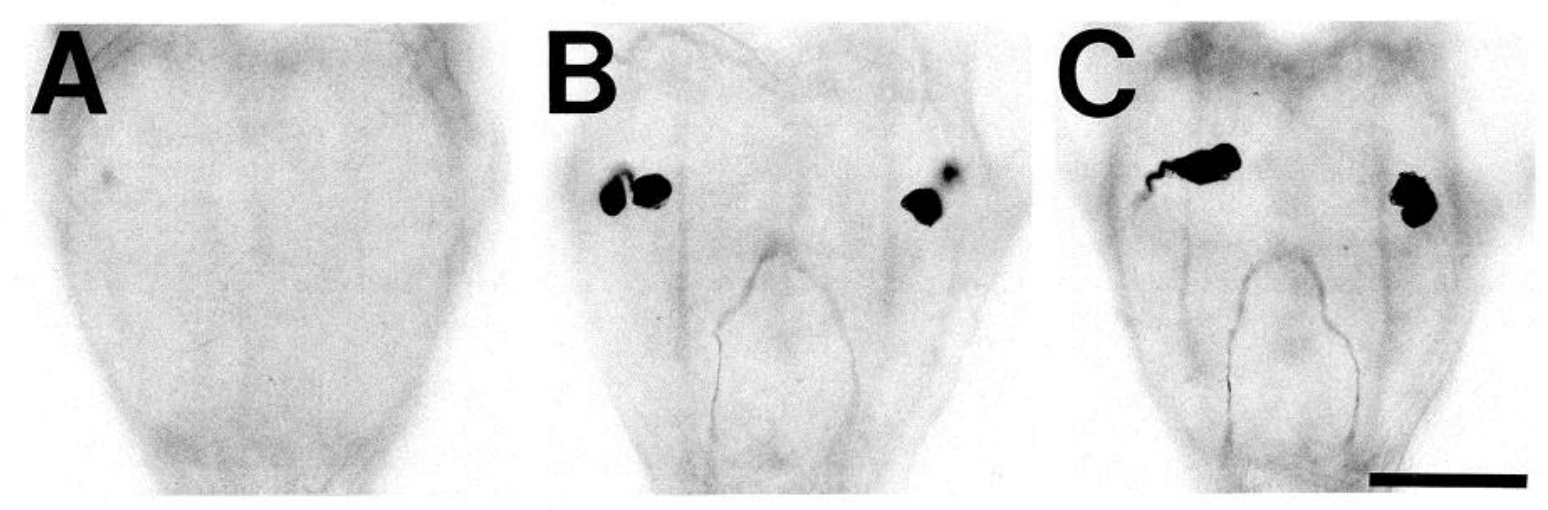

Figure 2. Pattern of cGMP-IR obtained in the third thoracic ganglion of larvae dissected 40 min after EH injection, using anti-cGMP antibody preabsorbed with, in $A, 10^{-5} \mathrm{M}$ cGMP; $B, 10^{-5} \mathrm{M}$ cAMP; and $C, 10^{-5} \mathrm{M}$ GMP. Scale bar, $150 \mu \mathrm{m}$. 

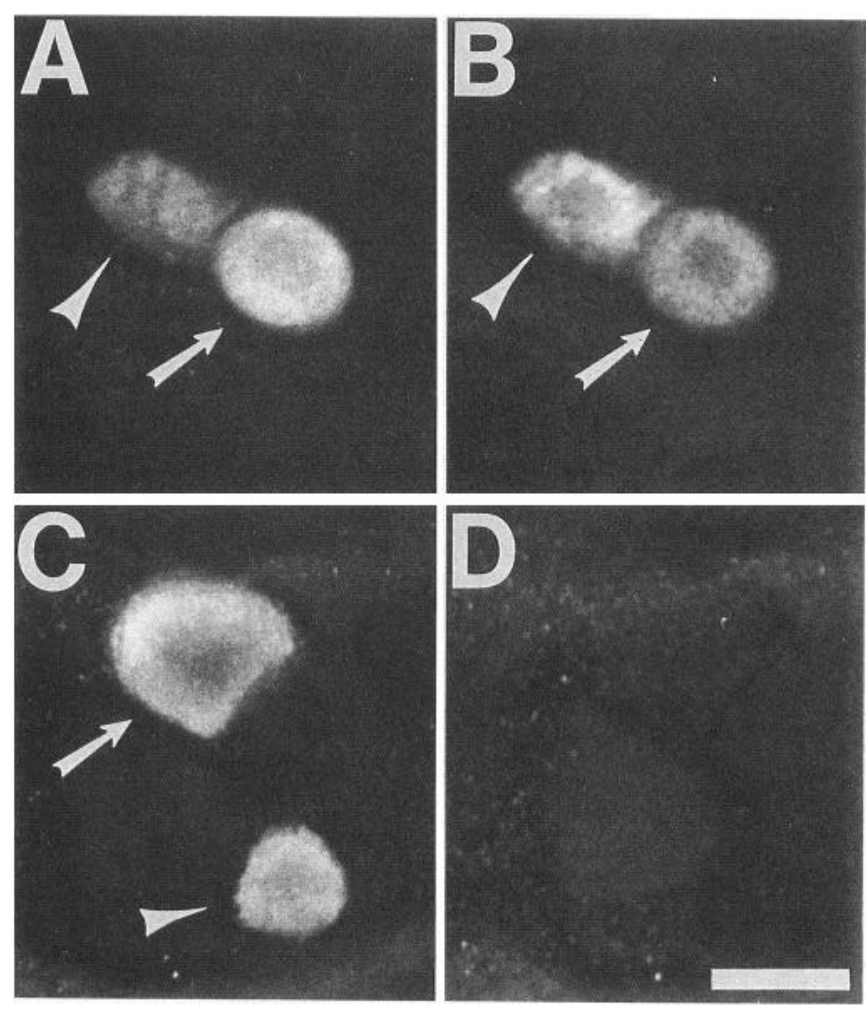

Figure 3. Confocal images showing co-localization of cGMP-IR to neurons immunoreactive to the neuropeptide CCAP. $A$, Abdominal neurons showing cGMP-IR; $B$, CCAP immunoreactivity (CCAP-IR) in the same neurons. Note that the intensity of cGMP-IR at this time was strongest in cell 27 (arrow), while that of CCAP-IR was strongest in interneuron 704 (arrowhead). $C$ and $D$, The homologous neurons in thoracic ganglia showing, in $C$, cGMP-IR; and $D$, no CCAP-IR. Scale bar, $25 \mu \mathrm{m}$.

immunoreactive when ganglia were taken a few hours prior to ecdysis (Fig. 1A). They became strongly immunoreactive at the time of ecdysis (Fig. $1 B$ ) and this staining then persisted for several hours (Fig. 1C). The immunostaining was severely reduced by preincubating the primary antibody with $10^{-5} \mathrm{M}$ CGMP (Fig. 2A), whereas it was unchanged when preincubated with $10^{-5} \mathrm{M}$ of either cAMP or GMP (Fig. 2, $B$ and $C$, respectively). Higher concentrations of cGMP abolished the immunostaining. Hence, as has been shown for mammalian tissues (De Vente et al., 1987), the immunostaining in insect CNS also appears to be specific for cGMP.

\section{Identity of cGMP-immunoreactive neurons}

Only 50 neurons in the entire CNS showed this robust increase in cGMP-IR (compare Fig. 4): five pairs of neurons in the subesophageal ganglion (SEG), and two pairs of neurons in each segmental ganglion from T1 through A7. Both pairs of neurons in each abdominal ganglion are peptidergic neurons that are immunoreactive for crustacean cardioactive peptide (CCAP; Fig. $3 A, B)$, a peptide that is present in the abdominal CNS of Man- duca (Cheung et al., 1992). One pair of these cells, Cell 27 (Taghert and Truman, 1982), are projection neurons that extend to the next posterior segment and terminate distally on the alary muscle of the heart and proximally in a neurohemal structure, the perivisceral organs (Davis et al., 1993). The second pair of cells (cell 704) are interneurons that show both anterior and posterior projections in the contralateral connectives (Davis et al., 1993). The morphology of the thoracic neurons indicates that they are the thoracic homologs of cells 27 and 704, but they lack CCAP immunoreactivity (Fig. $3 C, D$ ). One of the two most posterior pairs of SEG neurons is also a cell 27 homolog, which extends through the contralateral connective to $\mathrm{T} 1$ where it exits to the periphery through the dorsal nerve. The remaining SEG neurons have varied characteristics. The most anterior pair projects through the circumesophageal connective to the frontal ganglion. Another pair innervates the extrinsic musculature of the foregut. At least one of the remaining pairs is a descending interneuron (DIN) that extends through a dorsal tract to A8. At the level of the light microscope, the axon of this cell appears to make contact with each cell $27 /$ cell 704 pair as it traverses through the ventral ganglion. Thus, these 50 neurons appear to constitute an interconnected network of cells that is activated at the time of ecdysis.

In addition to these strongly cGMP-IR cells described here, a few other cells showed modest increases in cGMP-IR (not shown). These included one or two pairs of neurons usually found in ganglia A1 and A2, and a pair of smaller neurons in A8. These cells showed lower and variable levels of cGMP-IR and their axons were rarely stained.

\section{Time course of the cGMP response}

The temporal relationship of the activation of this network to $\mathrm{EH}$ action was determined by following the time course of the response in animals that were stimulated to undergo precocious ecdysis by injection of EH. As shown in Figures 4 and 5, only an occasional cell within the network showed weak cGMP-IR at the time of injection. The only cell showing strong staining was an A8 motoneuron that is thought to project to the rectum (Thorn and Truman, 1989). Interestingly, this neuron usually lost its cGMP-IR at the time of ecdysis and resumed expression of cGMP after ecdysis was complete.

The first behavioral response to injected $\mathrm{EH}$ began at $20 \mathrm{~min}$ (20 $\pm 0.9 ; N=26$ ) with the onset of preecdysis behavior (Copenhaver and Truman, 1982; Miles and Weeks, 1991). cGMPIR remained close to basal levels during the first 20-25 min but by $30-40 \mathrm{~min}$ all 50 neurons in the network showed prominent expression of cGMP-IR in their cell bodies and throughout their extensive dendritic and axonal arbors. Only an occasional animal dissected within the latter interval showed neurons in which the cGMP staining was incomplete. Thus, the increase in cGMP appears to spread throughout each neuron within the span of a few minutes. Ecdysis behavior began at about $45 \min (43 \pm$ $1.5 ; N=26$ ) after EH treatment, just after the network showed its peak of cGMP-IR expression (Figs. 4, 5).

Although the neurons showed relative synchrony in the in-

Figure 4. Time course of the EH-induced increase in cGMP. Each chain of ganglia shows camera lucida drawings of cGMP-IR in the ventral nervous system of animals dissected at the indicated times after exposure to EH. $S E G$, Subesophageal ganglion; $T 1-3$, thoracic ganglion T3 was drawn as a representative of the thoracic set; $A 1-6$, abdominal ganglion A5 was drawn as a representative of the abdominal set; $A 7$ and $A 8$, the terminal ganglia. 

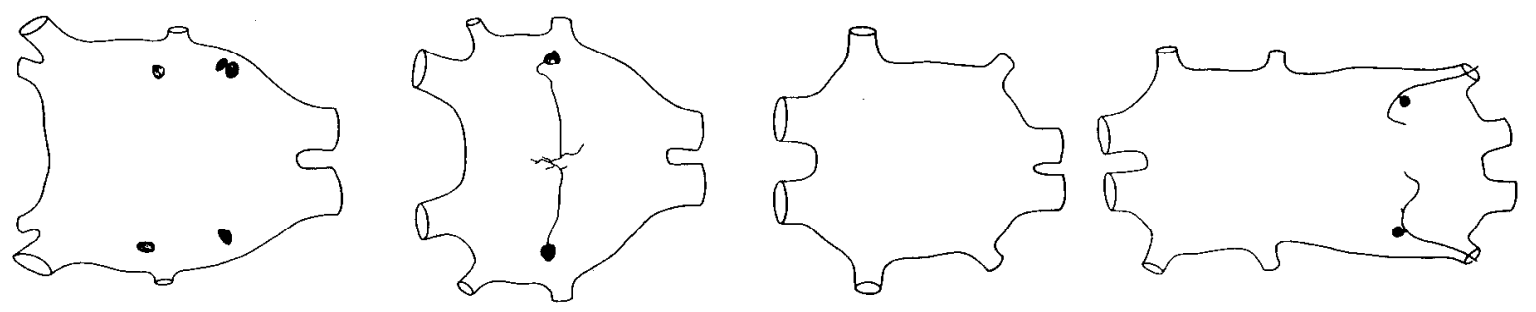

䢛貝
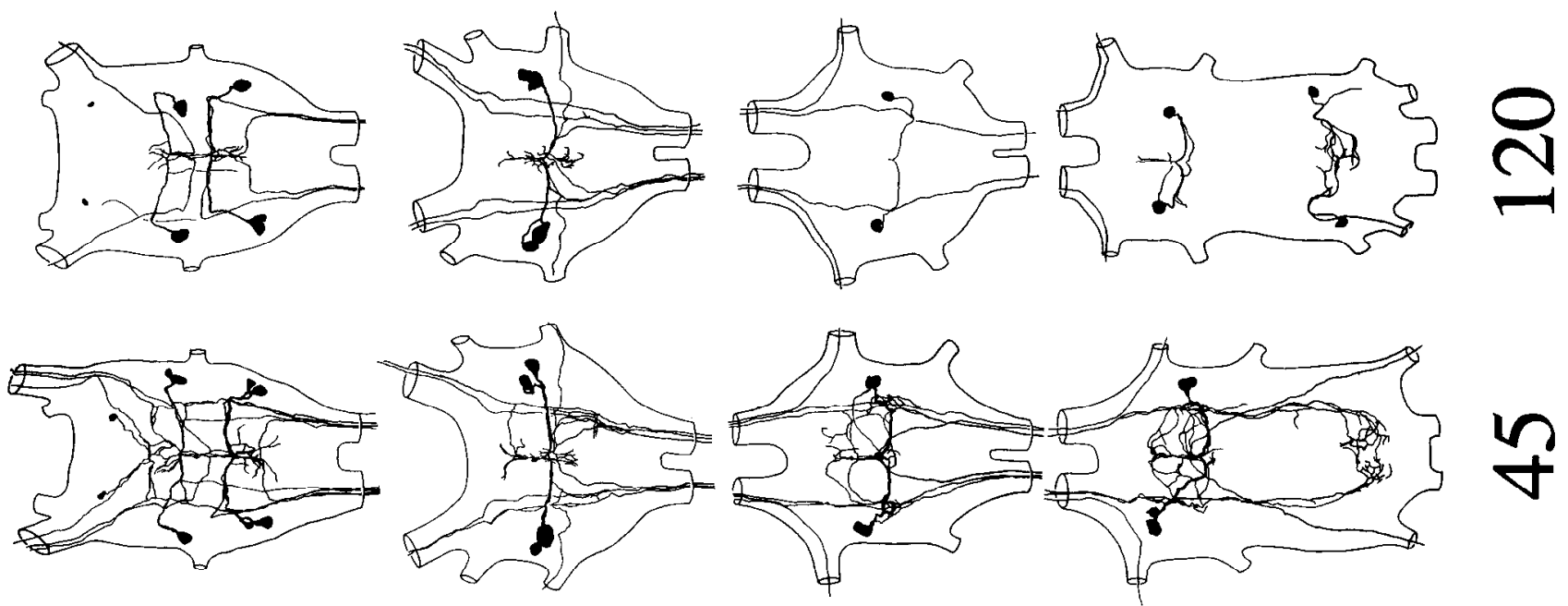

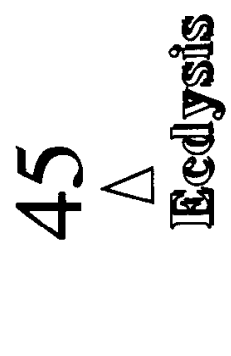
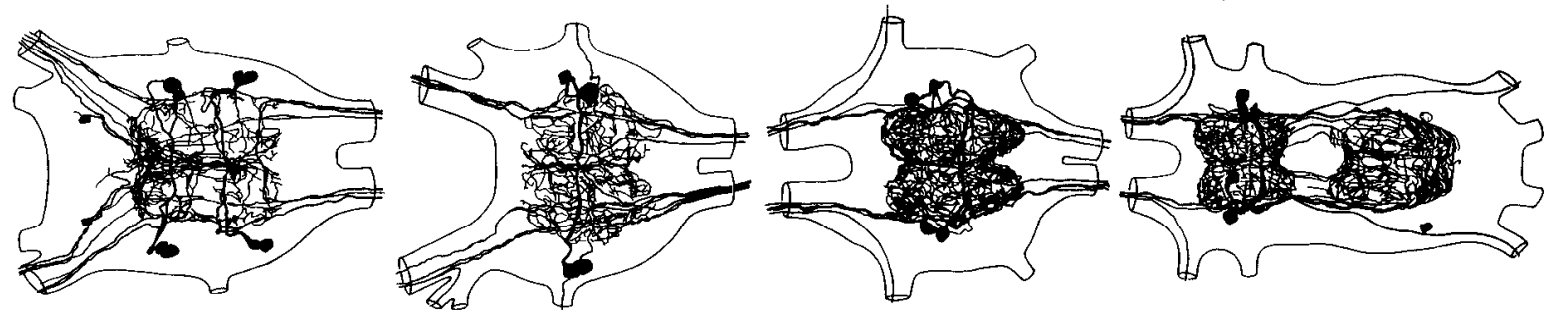

$m$
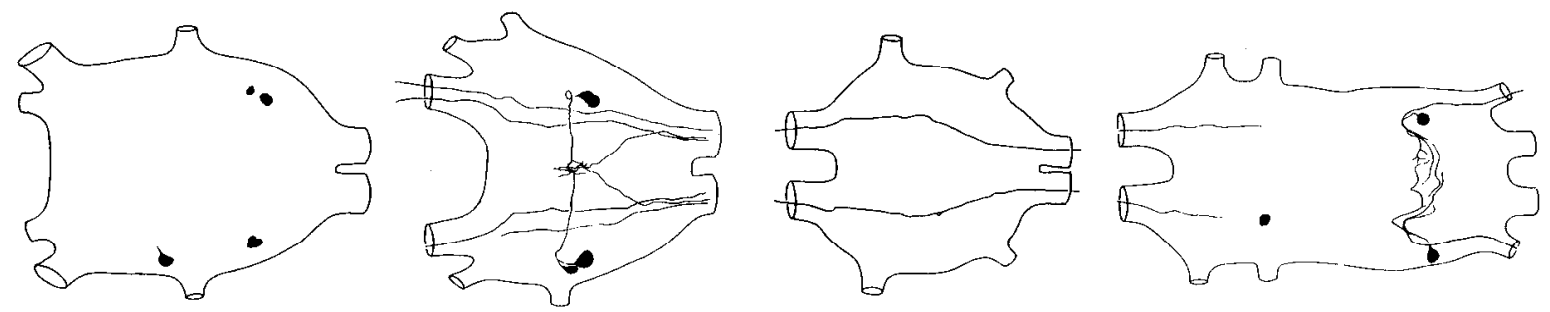

ก
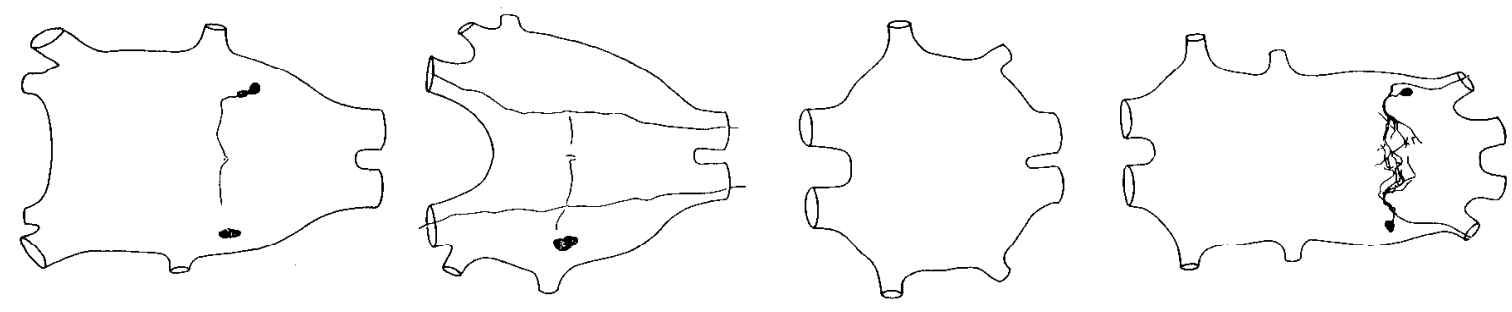

II

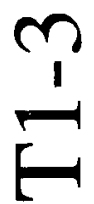

$\frac{1}{4}$

这文 


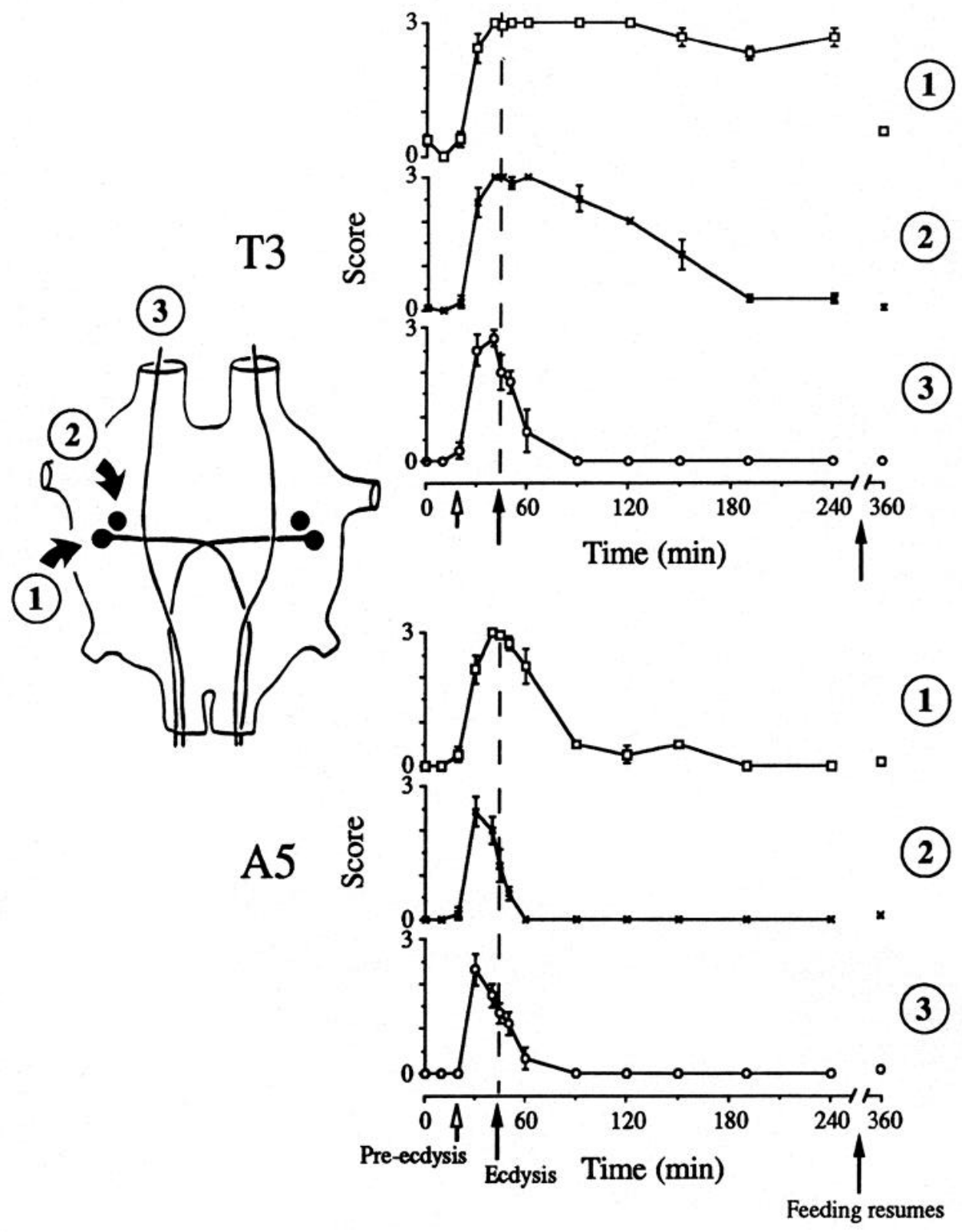

Figure 5. Time course of the EH-induced cGMP response. The intensity of the cGMP-IR in cell $27(1)$, interneuron 704 (2), and the dorsal descending axon of the SEG interneuron (3) (see inset), was assessed qualitatively by assigning scores to the staining intensity obtained at different times in similarly treated preparations. Scores of 3 and 0 correspond to maximal and background levels of staining, respectively. Each point represents the average \pm SEM for the number of preparations scored: 9 (at 50 and $360 \mathrm{~min}$ ), 8 (at $40 \mathrm{~min}$ ), 7 (at 45 $\mathrm{min}$ ), 6 (at 0 , and $30 \mathrm{~min}$ ), 5 (at 190 $\mathrm{min}$ ), 4 (at $20 \mathrm{~min}$ ), 3 (at $10,60,150$, and $250 \mathrm{~min}$ ), 2 (at 90 and $120 \mathrm{~min}$ ). duction of cGMP-IR, there was a striking variation in the length of time that specific cells maintained their elevated levels (Figs. $4,5)$. Among the first elements to lose their cGMP-IR were the axons of descending interneurons, which were immunonegative by $90 \mathrm{~min}$ after $\mathrm{EH}$ injection. In both the thoracic and the abdominal ganglia, the cGMP-IR was shorter-lived in interneuron 704 than in cell 27, but as seen in Figure 5, the cGMP response in the thoracic neurons far outlived that seen in their abdominal counterparts. Thus, for instance, the cell bodies and axons of the thoracic cell 27's were still immunopositive at 6 $\mathrm{hr}$ after EH injection whereas their abdominal homologs had lost their immunoreactivity by $3 \mathrm{hr}$. These differences in time course are intriguing, and suggest that the thoracic and abdominal neurons within this network play different roles during the ecdysis response. This notion is supported by the varied pattern of projection of these cells and by the fact that only the abdominal cells contain CCAP. Overall, the time course of the cGMP increase determined by immunostaining matches that measured biochemically from extracts of the abdominal CNS (Morton and Truman, 1985).

Since the peroxidase reaction with diaminobenzidine is nonlinear, we used fluorescently labeled antibodies and confocal microscopy to estimate the magnitude of the changes in cGMPIR observed during ecdysis. These results are summarized in Table 1, and show that the maximum levels of cGMP were 10100 -fold higher than the basal levels, observed prior to exposure to EH. In addition, they show that the relative changes in the levels of cGMP-IR seen at 0 (basal), 30-40 min, and $2 \mathrm{hr}$ after exposure to $\mathrm{EH}$ are consistent with the more subjective scoring system shown in Figure 5.

\section{The cGMP-IR increase is synaptically driven}

Insight into the mechanism by which $\mathrm{EH}$ evokes this increase in cGMP was provided by the response of larvae whose nerve cords had been transected prior to EH injection. Figure 6 shows the results obtained in an animal whose cord was cut between 


$\begin{aligned} & \text { Table 1. Relative changes in the intensity (average pixel intensity } \pm \\
& \text { SEM) of cGMP-IR in cells } 27 \text { and } 704 \text { in thoracic (T3) and } \\
& \text { abdominal (A5) neurons prior to EH injection (Basal), and at various } \\
& \text { times thereafter }\end{aligned}$
$\begin{aligned} & \text { Gan- } \\
& \text { glion }\end{aligned}$
\begin{tabular}{lrccr} 
Neuron & Basal & $30-40 \mathrm{~min}$ & $2 \mathrm{hr}$ \\
\hline T3 & 27 & $8 \pm 2(9)$ & $81 \pm 6(7)$ & $100 \pm 6(8)$ \\
& 704 & $2 \pm 1(9)$ & $100 \pm 7(7)$ & $77 \pm 7(8)$ \\
A5 & 27 & $0.5 \pm 0.5(8)$ & $100 \pm 15(7)$ & $21 \pm 8(6)$ \\
& 704 & $0.8 \pm 0.7(8)$ & $100 \pm 13(7)$ & $0 \pm 0.0(6)$
\end{tabular}

The number of neurons examined is indicated in parentheses.

abdominal ganglia 1 and 2, and was then challenged with $\mathrm{EH}$. When examined $60 \mathrm{~min}$ after injection a normal cGMP response was seen in the neurons anterior to the transection, whereas those posterior to it showed no response.

Table 2 summarizes the results obtained for transections made at different levels along the ventral cord. When the abdominal portion of the cord was transected at any level, the portion anterior to the lesion showed the full response whereas the posterior portion showed no response. Hence the increase in cGMP seen in the abdominal cells 27 and 704 is not a direct response to injected EH (or to any other blood-borne factor) but rather depends on input from descending units coming from the anterior region of the CNS. At this time the obvious candidates for this descending input are the SEG or thoracic members of this network whose axons project into the abdominal ganglia and appear to make contact with cells 27 and 704 .

The relationship of the response to EH in the thorax and SEG is more difficult to interpret. The results of the lesions show that these ganglia can generate a cGMP response in the absence of higher inputs but this response is very weak as compared to that seen normally. Consequently, these cells could be direct targets of $\mathrm{EH}$, but the full, normal response appears to require the brain, since the latter is only seen when a connection with the brain is intact.

In most systems examined so far cGMP responses are detected shortly after exposure to the relevant agonist. In contrast, as shown in Figures 4 and 5, we observed a delay of about $30 \mathrm{~min}$ between the time of the injection of EH and the synaptic activation of this network. In order to identify the source of this delay, we transected nerve cords at various times after injection of EH. Figure 7 and Table 3 show the results of such experiments, for cuts made between the brain and the SEG. The normal, robust cGMP response was obtained in more than half of the animals only when the connection to the brain was left intact for at least 25-30 min. Prior to this time, no such response was observed in the caudal portion, regardless of the time at which the larvae were subsequently processed for cGMP-IR. These results suggest that the lag time between exposure to $\mathrm{EH}$ and the cGMP elevation in the network represents the time required to activate the descending pathway. Since the time identified by the transection experiments is similar to the normal onset of cGMP expression, the cGMP response in these cells appears to be quite rapid once the descending signal is provided. An alternative, but less likely possibility, is that the descending pathway is rapidly activated upon exposure to $\mathrm{EH}$, but must drive the posterior neurons continuously for 25-30 $\mathrm{min}$ before they show cGMP elevations.
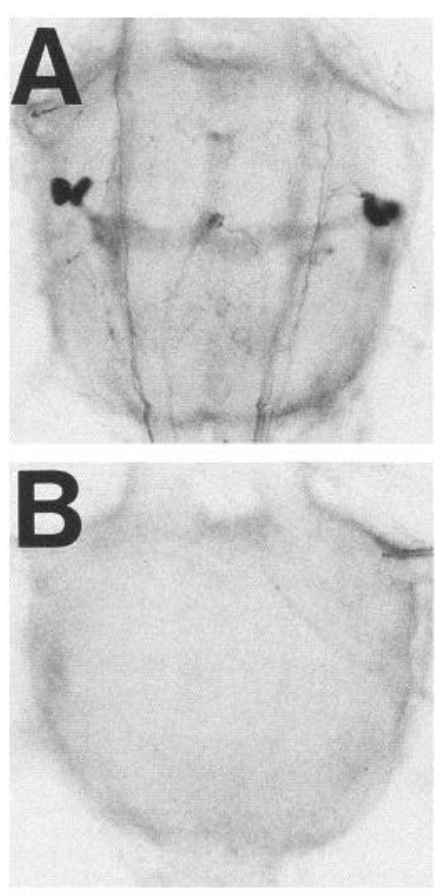

Figure 6. Example of the cGMP response in an animal in which the ventral nerve cord was transected prior to $\mathrm{EH}$ injection. $A$, Pattern cGMP-IR in ganglion A1, directly anterior to the transection, and representative of the cGMP-IR induced in all ganglia anterior it. $B$, Pattern of cGMP-IR observed in the ganglion A2, directly posterior to the cut. This absence of cGMP-IR was observed in all ganglia posterior to the cut.

The guanylate cyclase that is activated is not the soluble, nitric oxide (NO)-activated isozyme

One of the major biosynthetic pathways for cGMP involves the soluble form of guanylate cyclase (GC-S). GC-S can be activated by NO, a widespread intra- and intercellular mediator for a rapidly increasing number of agents (Garthwaite, 1991; Schmidt et al., 1993). Because of its significance, we examined whether GC-S was the form of guanylate cyclase that was activated by $\mathrm{EH}$. To this end we injected pharate larvae with the NO donor

Table 2. The effects of the level of nerve cord transection on the ability of ganglia to show an increase in cGMP-IR after EH treatment

\begin{tabular}{llrrr} 
& \multicolumn{4}{c}{ \% Response } \\
\cline { 3 - 5 } Level of transection & $N$ & Strong & Weak & None \\
\hline Br|SEG, unilateral & 5 & 100 & 0 & 0 \\
Br|SEG, bilateral & 8 & 0 & 75 & 25 \\
T1|T2 & 4 & 0 & 100 & 0 \\
T3|A1 & 3 & 0 & 0 & 100 \\
A1|A2 & 3 & 0 & 0 & 100 \\
A3|A4 & 2 & 0 & 0 & 100 \\
A5|A6 & 4 & 0 & 0 & 100 \\
A6|A7 & 2 & 0 & 0 & 100
\end{tabular}

Nervous systems were fixed at 90-120 min after EH treatment. Ganglia anterior to the transection invariably showed a full response; those posterior to the lesion showed similar responses, which were scored as strong (a normal response), weak (only a few neurons in the SEG or thoracic ganglia responding weakly), or none. $N$ refers to the number of animals tested. 


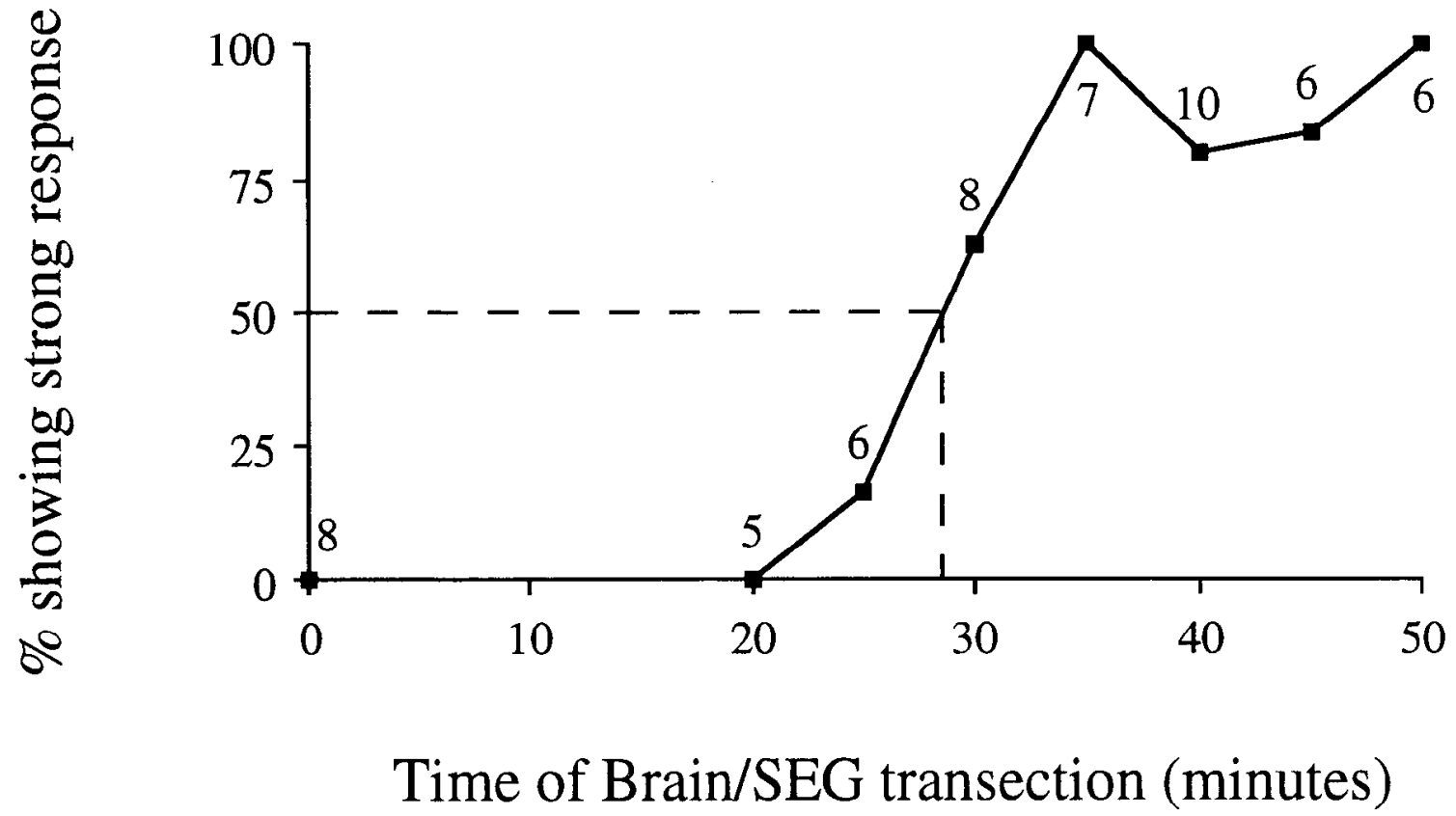

Figure 7. Percentage of larvae showing normal (strong) increases in cGMP-IR after removal of the brain at various times after EH injection. Numbers indicate the number of animals tested at each time. Animals were dissected at $90-120$ min after injection and processed for cGMP-IR. A response was considered normal if all the cGMP-IR cells in T3 had a score of 2 or 3 (compare Fig. 5).

sodium nitroprusside (SNP), and processed the CNS for cGMPIR. As illustrated in Figure 8, SNP induced intense cGMP-IR in a small number of neurons. Interestingly, however, none of these corresponded to the neurons that show high levels of cGMPIR after EH treatment.

\section{Discussion}

The insect neuropeptide EH acts on the CNS to evoke a stereotyped sequence of behaviors that are used for shedding the old cuticle at the end of each molt. These actions of EH can be mimicked by injection of cGMP (but not cAMP) and EH exposure induces a persistent elevation in cGMP in the CNS (Truman et al., 1979; Morton and Truman, 1985). The results reported here indicate that the cGMP increase is due primarily to changes occurring within a small set of 50 neurons within the CNS.

While many transmitters, peptides, and hormones are known to effect changes in the levels of particular second messengers,

\begin{tabular}{lcc}
\hline $\begin{array}{l}\text { Table 3. The effects of time of brain/ SEG transection (after EH } \\
\text { treatment) on the ability of the ventral CNS to show an increase in } \\
\text { cGMP-IR } \\
\text { Time of lesion (min) }\end{array}$ & $N$ & \% Strong \\
\hline 0 & 8 & 0 \\
20 & 5 & 0 \\
25 & 6 & 17 \\
30 & 8 & 63 \\
35 & 7 & 100 \\
40 & 10 & 80 \\
45 & 6 & 83 \\
50 & 6 & 100
\end{tabular}

Ganglia were fixed 90-120 min after injection and their cGMP-IR was scored as described in Table 2 notes. $N$ refers to the number of animals tested. the features of the cGMP response shown by these neurons at ecdysis show a number of novel features. The response occurs as the result of the normal action of a neuropeptide, and is confined to a small network of apparently synaptically connected neurons. The cGMP increase is an extremely long-lived response, which is still detectable in some cells after $6 \mathrm{hr}$.

\section{Role of synaptic interactions in the EH-induced increase in cGMP}

The manner by which EH stimulates cGMP is controversial. Biochemical results obtained using the abdominal CNS of Manduca suggest that EH stimulates CGMP via metabolites of arachidonic acid (Morton and Giunta, 1992). In contrast, experiments in the commercial silkworm, Bombyx mori, on saponin-treated ganglia support a pathway leading from inositol triphosphate production and through subsequent calcium activation of nitric oxide synthase and, hence, to the soluble guanylatc cyclase (Shibanaka et al., 1993, 1994). The immunocytochemical results reported here reveal an unexpected complexity in the involvement of cGMP with ecdysis. The biochemical measurements of cGMP in CNS extracts of Manduca (Morton and Truman, 1985) and Bombyx (Shibanaka et al., 1991) show a moderate increase in cGMP occurring within 5-10 min after EH treatment with maximum levels seen only at the time of ecdysis. The attainment of maximal levels coincides with the delayed increase seen in the network described here. The transection experiments, though, show that $\mathrm{EH}$ is not sufficient for triggering the latter cGMP increase, at least for the majority of cells in this group.

Consequently, cGMP appears to be involved in two distinct responses during ecdysis. Presumed EH target cells show a rapid, but moderate response to $\mathrm{EH}$ and may be represented by the weak-staining cells that we occasionally observe. This activation may involve arachidonic acid metabolites or a NO activated pathway. Downstream of this action, cGMP plays a second role 

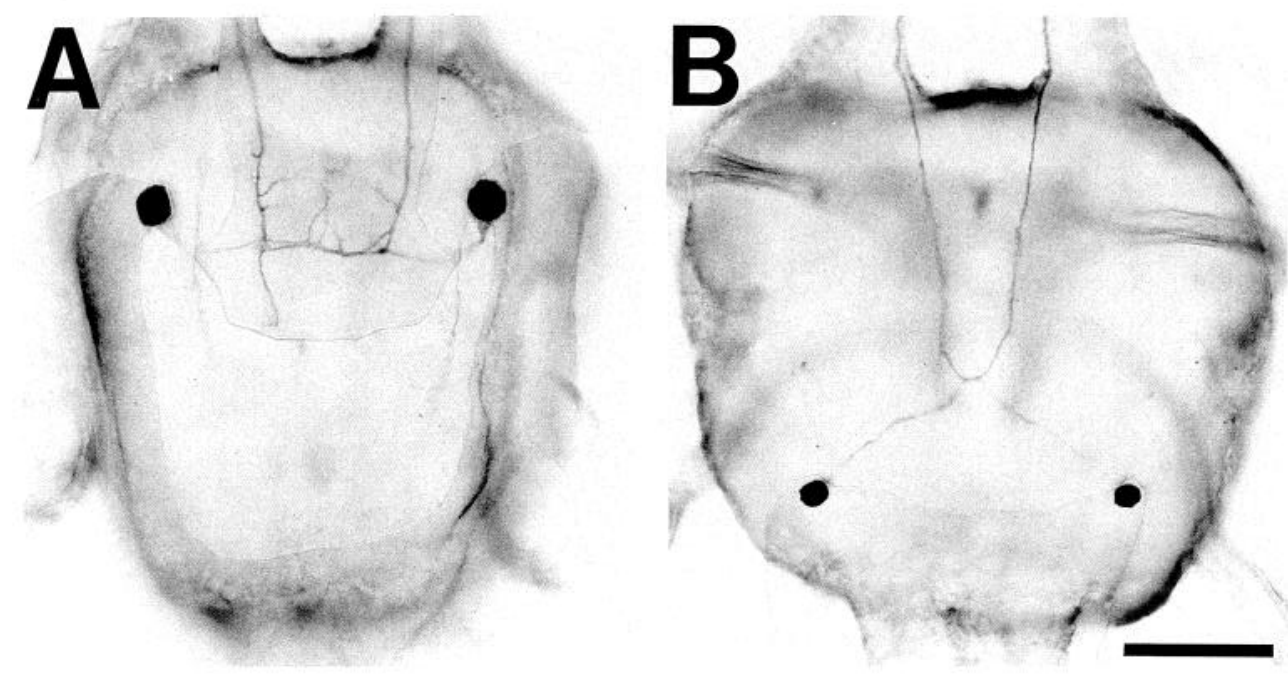

Figure 8. Photomontage of examples of cGMP-IR neurons in a thoracic (T3; $A$ ) and an abdominal (A6;B) ganglion in larvae injected with the NO-donor SNP. Scale bar, $100 \mu \mathrm{m}$. in the activation of the group of 50 neurons at ecdysis. This cGMP increase requires stimulation by descending units, and appears not to involve NO.

\section{Cell-specific cGMP responses to hormone}

The spectrum of cells that become cGMP immunoreactive at ecdysis is of interest considering the physiological changes that occur at this time. Air swallowing is a prominent feature of ecdysis in most insects including Manduca. This behavior likely involves some of the cGMP-IR neurons in the SEG, since one pair innervates the foregut and another extends to the frontal ganglion, which is associated with swallowing (Griss et al., 1991). Also, at ecdysis there are major adjustments in cardiac activity as blood is redistributed to aid in rupturing the old cuticle and expanding the new one. Indeed, adult ecdysis in Manduca is accompanied by a release of cardioactive peptides (Tublitz and Truman, 1985), one of which is CCAP (Cheung et al., 1992). The cell $27 \mathrm{~s}$ in the abdomen are the main neurosecretory cells that contain CCAP and would be involved in this release. Hence, the cGMP response appears to involve neurons that may mediate the visceromotor and cardiac adjustments that accompany ecdysis. The timing of the activation of the network is interesting. It occurs after the onset of preecdysis behavior but before the start of ecdysis. This temporal relationship presents the intriguing possibility that this network might be the proximate trigger that initiates the ecdysis motor program. This possible initiating role aside, the anatomy of the network is not consistent with these cells being involved in the actual patterning of the ecdysis movements.

\section{Mechanism of spread of cGMP response}

In the case of the abdominal cell 27's, their activation by descending units presumably occurs within the ganglion, but the cGMP appears to spread along $5 \mathrm{~mm}$ of axon in the connectives and peripheral nerves within less than a few minutes. The extent of this spread through the axon indicates that it cannot be due to simple diffusion of cGMP from the dendrites but must be due to activation of guanylate cyclase that is distributed throughout the cell including the dendrites, cell body and axon. We envision two possible mechanisms by which this activation could occur within cell 27 . One is that the firing of the cell could result in $\mathrm{Ca}^{2+}$ entry along the length of the axon, which, in turn, activates the guanylate cyclase (Ogura et al., 1986). Alternatively, the spread could occur through a regenerative diffusionbased wave in which elevations of cGMP would directly or indirectly stimulate the cyclase. Such a mechanism has not yet been described for cGMP but it would be analogous to the calcium-induced calcium release that propels calcium waves through cells (Berridge, 1993). The time resolution of the experiments reported here do not allow us to distinguish between the above two possibilities. Irrespective of the mechanism, the observations on cell 27 suggest that there exists a mechanism by which cyclic nucleotide changes in one part of a cell can spread to remote regions of the same cell within the span of a few minutes. In the case of cell 27 , the direction of spread is anterograde. In other contexts, a similar mechanism might be used for retrograde signaling from axon terminals or growth cones to the cell body.

\section{cGMP as a long-lasting second messenger}

While increases in second messenger levels at the single cell level have been documented previously, they are usually more transient. Such is the case for changes in the levels of $\mathrm{Ca}^{2+}$ in cerebellar Purkinje cells (Tank et al., 1988; Sugimori and Llinás, 1990), cAMP in Aplysia sensory neurons (Bacskai et al., 1993) and cGMP in photoreceptor cells (Yau and Baylor, 1989). Interestingly, though, the responses that involve changes in cGMF levels show some of the longest time courses. For example, bath application of atrial natriuretic peptide induced a rise in cGMP in hippocampal slices that started to show a reduction only after $20 \mathrm{~min}$ (De Vente and Steinbusch, 1992). This observation suggests that cGMP may be preferentially used in those cases in which a brief exposure to an agonist induces a long-lasting change in second messenger levels.

\section{Function of cGMP response}

One of the open questions is the effects of the increase of cGMP in these cells. A likely possibility is that it leads to changes in neuronal excitability, and this hypothesis is consistent with the reports of the release of CCAP at the time of ecdysis (Tublitz and Truman, 1985; Cheung et al., 1992). Such changes could be achieved by the direct gating of ionic channel by cGMP, as is known to occur in photoreceptor and olfactory neurons (Latorre et al., 1991), or by modifying their kinetic properties by 
phosphorylation, which accounts, for instance, for the increase in calcium current of some snail neurons (Paupardin-Tritsch et al., 1986).

The decay of the EH-induced cGMP increase differs markedly among individual neurons. This differential decay could provide a mechanism whereby neurons with different roles can remain active for the appropriate length of time following their concerted activation, and may thereby allow for the orchestration of hormone-induced actions that have different durations.

We have shown here that an insect neuropeptide triggers a long lasting increase in cGMP in a small network of identified neurons. The various features of this response make this preparation ideally suited to ask questions that are relevant to the action of peptides and second messengers in the CNS at the behavioral, physiological, and biophysical levels.

\section{References}

Bacskai BJ, Hochner B, Mahaut-Smith M, Adams SR, Kaang B-K, Kandel ER, Tsien RY (1993) Spatially resolved dynamics of cAMP and protein kinase A subunits in Aplysia sensory neurons. Science 260:222-226.

Berridge MJ (1993) Inositol triphosphate and calcium signalling. Nature 361:315-325.

Butt E, Geiger J, Jarchau T, Lohmann SM, Walter U (1993) The cGMP-dependent protein kinase-gene, protein, and function. Neurochem Res 18:27-42.

Cheung CC, Loi PK, Sylwester AW, Lee TD, Tublitz NJ (1992) Primary structure of a cardioactive neuropeptide from the tobacco hawkmoth Manduca sexta. FEBS Lett 313:165-168.

Copenhaver PF, Truman JW (1982) The role of eclosion hormone in the larval ecdyses of Manduca sexta. J Insect Physiol 28:695-701.

Davis NT, Homberg U, Dircksen H, Levine RB, Hildebrand JG (1993) Crustacean cardioactive peptide-immunoreactive neurons in the hawkmoth Manduca sexta and changes in their immunoreactivity during postembryonic development. J Comp Neurol 338:612-627.

De Vente J, Steinbusch HWM (1992) On the stimulation of soluble and particulate guanylate cyclase in the rat brain and the involvement of nitric oxide as studied by cGMP immunohistochemistry. Acta Histochem 92:13-38.

De Vente J, Steinbusch HWM, Schipper J (1987) A new approach to immunocytochemistry of $3^{\prime}, 5^{\prime}$-cyclic guanosine monophosphate: preparation, specificity, and initial application of a new antiserum against formaldehyde-fixed $3^{\prime}, 5^{\prime}$-cyclic guanosine monophosphate. Neuroscience 22:361-373.

Eldridge R, I Iorodyski FM, Morton DB, O'Reilly DR, Truman JW, Riddiford LM, Miller LK (1991) Expression of an eclosion hormone gene in insect cells using baculovirus vectors. Insect Biochem 21:341351.

Ephrussi B, Beadle AW (1936) A technique of transplantation for Drosophila. Am Nat 70:218-225.

Garthwaite J (1991) Glutamate, nitric oxide, and cell-cell signalling in the nervous system. Trends Neurosci 14:60-67.

Goy MF (1991) cGMP: the wayward child of the cyclic nucleotide family. Trends Neurosci 14:293-299.

Griss C, Simpson SJ, Rohrbacher J, Rowell CHF (1991) Localization in the nervous system of larval Manduca sexta (Lepidoptera: Sphingidae) of areas responsible for aspects of feeding behavior. J Insect Physiol 37:477-482.

Latorre R, Bacigalupo J, Delgado R, Labarca P (1991) Four cases of direct ion channel gating by cyclic nucleotides. J Bioenerg Biomem 23:577-597.
Mesce KA, Klukas KA, Brelje TC (1993) Improvements for the anatomical characterization of insect neurons in whole mount: the use of cyanine-derived fluorophores and laser scanning microscopy. Cell Tissue Res 271:381-397.

Miles CI, Weeks JC (1991) Developmental attenuation of the preecdysis motor pattern in the tobacco hornworm, Manduca sexta. $\mathrm{J}$ Comp Physiol [A] 168:179-190.

Morton DB, Giunta MA (1992) Eclosion hormone stimulates cyclic GMP levels in Manduca sexta nervous tissue via arachidonic acid metabolism with little or no contribution of nitric oxide. J Neurochem 59:1522-1530.

Morton DB, Truman JW (1985) Steroid regulation of the peptidemediated increase in cGMP in the nervous system of the hawkmoth, Manduca sexta. J Comp Physiol 157:423-432.

Ogura A, Ozaki K, Kudo Y, Amano T (1986) Cytosolic calcium elevation and cGMP production induced by serotonin in a clonal cell of glial origin. J Neurosci 6:2489-2494.

Paupardin-Tritsch D, Hammond C, Gerschenfeld HM, Nairn AC, Greengard P (1986) cGMP-dependent protein kinase enhances $\mathrm{Ca}^{2+}$ current and potentiates the serotonin-induced $\mathrm{Ca}^{2+}$ current increase in snail neurons. Nature 323:812-814.

Schmidt HHHW, Lohmann SM, Walter U (1993) The nitric oxide and cGMP signal transduction system: regulation and mechanism of action. Biochem Biophys Acta 1178:153-175.

Schwartz LM, Truman JW (1984) Cyclic GMP may serve as a second messenger in peptide-induced muscle degeneration in an insect. Proc Natl Acad Sci USA 81:6718-6722.

Shibanaka Y, Hayashi H, Okada N, Fujita N (1991) The crucial role of cGMP in the eclosion hormone mediated signal transduction in the silkworm metamorphoses. Biochem Biophys Res Commun 180: 881-886.

Shibanaka Y, Hayashi H, Takai M, Fujita N (1993) Eclosion hormone activates phosphatidylinositol hydrolysis in silkworm abdominal ganglia during adult metamorphosis. Eur J Biochem 221:427-430.

Shibanaka Y, Hayashi H, Umemura I, Fujisawa Y, Okamoto M, Takai M, Fujita N (1994) Eclosion hormone-mediated signal transduction in the silkworm abdominal ganglia: involvement of a cascade from inositol $(1,4,5)$ triphosphate to cyclic GMP. Biochem Biophys Res Commun 198:613-618.

Sugimori M, Llinás RR (1990) Real-time imaging of calcium influx in mammalian cerebellar Purkinje cells in vitro. Proc Natl Acad Sci USA 87:5084-5088.

Taghert PH, Truman JW (1982) Identification of the bursicon-containing neurones in abdominal ganglia of the tobacco hornworm, Manduca sexta. J Exp Biol 98:385-401.

Tank DW, Sugimori M, Connor JA, Llinás RR (1988) Spatially rcsolved calcium dynamics of mammalian purkinje cells in cerebellar slices. Science 242:773-777.

Thorn RS, Truman JW (1989) Sex-specific neuronal respecification during the metamorphosis of the genital segments of the tobacco hornworm moth Manduca sexta. J Comp Neurol 284:489-503.

Truman JW (1992) The eclosion hormone system of insects. Prog Brain Res 92:361-374.

Truman JW, Mumby SM, Welch SK (1979) Involvement of cyclic GMP in the release of stereotyped behavior patterns in moths by a peptide hormone. J Exp Biol 84:201-212.

Tublitz NJ, Truman JW (1985) Insect cardioactive peptides. I. Distribution and molecular characteristics of two cardioacceleratory peptides in the tobacco hawkmoth, Manduca sexta. J Exp Biol 114:365379.

Yau K-W, Baylor DA (1989) Cyclic GMP-activated conductance of retinal photoreceptor cells. Annu Rev Neurosci 12:289-327. 